\title{
6.2 Formation and analysis of project cash flows
}

The orientation of economic systems mainly towards market methods of management becomes the reason for the active interest of economists and practitioners in monetary factors when organizing new projects. Nowadays, especially in crisis conditions of non-payments, consideration of the most important aspects of the content of the project's cash turnover acquires special relevance.

Non-profit assets, namely cash, are required to purchase equipment, materials and raw materials, payment for transportation and other services, wages, and repayment of creditors.

The chosen topic is relevant since the existence and profitability of the project depends on the establishment of a lower limit for the balance of funds in national and foreign currencies, which will be sufficient to:

- timely pay suppliers' bills, which will allow discounts on the price of goods;

- maintain creditworthiness;

- pay for unforeseen expenses that may arise in the process.

To solve this problem, it is necessary to take into account that when immobilizing monetary resources as an irreducible balance of money on the account, it is associated with some losses for the project; with a certain degree of convention, their value can be estimated by the amount of lost benefits. Thus, it is advisable to take into account two circumstances: maintaining the current solvency and obtaining additional profit from the investment of free funds.

The main purpose of the work is to analyze cash flows using the example of an operating enterprise, for which the tasks of assessing cash flows using direct and indirect methods, the method of coefficients are set.

A number of factors affect the decision-making on how much cash you need to have at your disposal, taking into account the liquid assets of the enterprise, financial risk, the volume of debt obligations and the timing of their repayment, the ability to obtain bank loans in a short time and for favorable conditions. First-class borrowers in terms of creditworthiness, who are able to obtain loans at favorable interest rates, can 
afford a lower level of funds than firms with a high proportion of leveraged funds in the balance sheet liabilities or with a higher credit risk. In order to reveal the real cash flow at the enterprise, to assess the safety of their receipts and expenditures, as well as to link the size of the financial result with the availability of money at the enterprise, it is advisable to analyze all directions of the inflow and outflow of cash resources.

In order to carry out its expenses, the project needs to ensure an adequate inflow of money supply and revenues. Roofing felts from the sale of manufactured products, goods (services, works), receipt of temporary borrowed funds, it is possible to receive dividends on the invested capital. Which means that the activity of the project is an objective prerequisite for the emergence of cash flow.

Cash flow is created by the movement of project funds over time and is an ongoing process.

Cash flow is the aggregate of the volumes of cash outflows and inflows distributed over time in the course of the economic activity of the project. A positive cash flow is a cash inflow or inflow.

The disposal or outflow of cash is called negative cash flow. Net cash flow is the difference between negative and positive cash flows for each type of activity or economic activity of the project as a whole. The concept of cash flow is generalized and contains a large number of different types of cash flows that arise during the operation of the project. In order to provide a comprehensive, in-depth analysis, the cash flows of the project must be classified according to a number of such basic characteristics:

I. By type of activity: operating; investment; financial.

2. For participation in the business process: for the project as a whole; by the types of his economic activities; by project directions; for individual business transactions

3. Direction: negative cash flow; positive cash flow.

4. By the level of optimality: scarce cash flow; excess cash flow.

5. By time: planned cash flow; operational cash flow.

6. At the moment of valuation of cash: future and present value of cash flows. 
7. By the nature of the formation: periodic or regular cash flow; episodic or discrete cash flow.

8. By time intervals: cash flow with regular and irregular intervals.

In order to carry out the normal life of the project, it must have the optimal amount of funds. Lack of funds can negatively affect the activities of the project and lead to unprofitability, loss-making, decrease in liquidity and even the winding down of the project.

Excess cash can also have a negative impact on the project. Surplus funds or money supply that are not involved in production and commercial turnover does not increase income. Inflationary processes affect the real value of money, by devaluing them over time. To make optimal management decisions related to the movement of funds, in order to achieve the best effect of economic activity, the project management needs constant awareness of the state of funds. From which it follows that both a systematic detailed analysis and an assessment of the project's cash flows are needed. The role of cash flow analysis is very important because the analysis creates the basis for the formation of an effective and correct policy for making managerial decisions by the project management, its significance is due to a number of reasons:

- the project, in almost all aspects of its activity, cash flows serve its functioning;

- financial stability and solvency of the project ensure optimal cash flows;

- the rationalization of cash flows contributes to the achievement of the rhythm of the production and commercial process of the project;

- the project's need for attracting borrowed capital is reduced through effective cash flow management;

- a prerequisite for accelerating the turnover of the project's capital as a whole is the optimization of cash flows;

- expansion of the scale of production and growth of proceeds from the sale of products, goods (services, works), the receipt of additional income is ensured through the rational use of freed up funds as a result of optimization of cash flows. The purpose of the analysis of cash flows is to obtain the required volume of their parameters, which give objective, reliable, accurate and timely characteristics of the directions of receipts and 
expenditures of funds, composition, volumes, structure, both objective and subjective, both external and internal factors that have a different effect on the change in cash flows.

Tasks of the analysis of project cash flows:

- assessment of cash flows by type of economic activity;

- assessment of the optimality of the organization's cash flows

- assessment of both the composition and the structure, including the directions of cash flow;

- assessment of the dynamics of cash flows;

- identification and measurement of the degree of influence of various factors on the formation of cash flows;

- both identification and assessment of reserves for improving the operation of cash;

- development of offers for the sale of reserves to improve the efficiency of the operation of funds.

Substantiation of the degree of sufficiency or insufficiency of the formation of the volume of money supply as a whole, including by type of activity, the balance of both positive and negative cash flows in terms of volume and time is one of the main directions of the analysis of cash flows. Together with the analysis of cash flows as a whole for the project, it is advisable to carry it out in separate areas. The first stage of the analysis includes consideration of the dynamics of the volume of formation of the positive cash flow of the project (i.e., cash flow) from the point of view of individual sources. It would be advisable to compare the growth rate of positive cash flow with the growth rate of assets, sales, revenue volumes, with different profit indicators. It is necessary to pay special attention to the ratio of the sources of formation of a positive cash flow of its internal (sales proceeds) and external (such as received loans, credits), determining the degree of dependence on external sources.

At the second stage, the dynamics of the volume of the negative cash flow of the project is studied, which is the outflow of funds, including its structure in the direction of spending money. 
The third stage is the analysis of the balance of negative and positive cash flows in terms of their total volume. The dynamics of the net cash flow is analyzed and makes it possible to assess the result of the project, since the net cash flow is almost the most important indicator of the balance of production and financial activities. During the fourth stage, the analysis determines the role and place of the net profit indicator for the formation of net cash flow, the influence on it of various factors: accounts receivable and payable, changes in the amount of inventory balances, created reserves, accrued depreciation during the analyzed period. A special place is given to the characteristic of the quality of the net cash flow, namely to the indicators of the structure of the sources of its formation. A high level of quality of net cash flow is characterized by an increase in the proportion of net profit received due to an increase in sales proceeds and a decrease in costs.

Low quality is characterized by net cash flow, in which a significant part is obtained due to the increase in sales prices, income from non-sales operations associated with inflationary processes, extraordinary income.

Coefficient analysis, where the necessary indicators are calculated, which characterize the efficiency of the use of the project's funds, are carried out at the fifth stage. With the help of various coefficients, the modeling of factor systems is carried out in order to identify and quantitatively measure the reserves for the growth of the efficiency of cash flow management. There is a very significant drawback in the direct method of analyzing cash flows: it will not allow analyzing the influence of various factors on the subject of changes in the balance of funds in conjunction with changes in those indicators that form the financial results of the project. For this purpose, it uses an indirect method.

In this regard, it is necessary to carry out a number of adjustments, as a result of which the value of the net profit of the reporting period becomes equal to the increase in cash. Such adjustments are conventionally divided into three groups according to the nature of business operations:

Adjustments related to the discrepancy between the time of reflection of income and expenses in accounting with the inflow and outflow of funds for these operations. 
An example of such operations is the reflection in the accounting of proceeds from the sale of goods, products (works, services) with the provision of deferred payment to buyers. In this case, the accounting reflects the amount of revenue, but the corresponding cash inflow in this reporting period may not occur. Consequently, it is necessary to adjust the net profit indicator towards its decrease by the amount of growth in the balance of accounts receivable. And vice versa, with an increase in the amount of advances received in the form of an advance payment for future deliveries of goods, products (works, services), it is necessary to increase the amount of net profit of the reporting period by this amount.

Adjustments related to business transactions that do not directly affect the calculation of net income, but generate cash flows. In particular, the payment for the purchase of raw materials and materials and the adequate growth of the balances of tangible current assets in the analyzed period necessitates adjustments to the amount of net profit. With an increase in the balances of tangible current assets, the amount of net profit should be reduced by this amount, and with a decrease, it should be increased. Another example of this group of adjustments can be business transactions that cause a change in the short-term and long-term obligations of the organization. So, the inflow or outflow of funds in connection with the attraction or return of borrowed funds (loans, borrowings) does not cause a similar change in the financial result. Therefore, if the balances of the corresponding accounts change, the amount of net profit of the reporting period is also subject to adjustment: with their growth, the profit should be increased, with a decrease, it should be reduced.

Adjustments related to transactions that have a direct impact on the calculation of the profit indicator, but do not cause cash flows. An example of such a transaction is the accrual of depreciation of fixed assets, intangible assets, low-value and wearing out items. The amount of net profit should be adjusted upwards by the amount of accrued depreciation; for the reporting period. Correction procedures affect the overwhelming part of balance sheet accounts, and calculations should be made based on the proposed general rule: in order to achieve a correspondence between the amount of the increase in cash balances and the adjusted amount of net profit, it is necessary to 
increase the net profit by the amount of capital gains (equity and borrowed sources). $\neg$ nikov funds) and reduce by the amount of the increment of assets (non-circulating, circulating). Moreover, it should be borne in mind that the amount of the increment can be both positive and negative.

Based on the results of direct and indirect analysis of cash flows, the management of the organization can adjust its financial policy in relations with debtors and creditors, make decisions on the formation of the necessary volumes of inventories, create reserves, reinvest profits, distribute and consume them, taking into account available financial capabilities and the level of security with monetary resources.

Ratio analysis is an integral part of cash flow analysis. With its help, the levels and their deviations from the planned and baseline values of various relative indicators characterizing cash flows are studied, and the coefficients of the efficiency of using the organization's funds are calculated.

An important point in the coefficient method of analysis is the study of the dynamics of various coefficients, which makes it possible to establish positive and negative trends reflecting the quality of the organization's cash flow management, as well as to develop the necessary measures to make appropriate adjustments to optimize management decisions in business process.

An important point in the analysis of cash flows is the assessment of their balance in time, deviations of multidirectional cash flows in separate time intervals. In this case, it is necessary to proceed from the criterion of minimization of possible deviations (fluctuations) in the values of the inflow and outflow of funds.

To establish the degree of synchronicity (balance) of cash flows for the analyzed period, the correlation coefficient of positive and negative cash flows is used.

The closer the value of the correlation coefficient of cash flows to one, the less the variation of fluctuations between the values of positive and negative cash flows, therefore, the less the risk of a situation of insolvency, on the one hand (in periods of excess of the values of negative cash flows over positive), and the excess of the money supply - on the other hand, testifying to the lost profit of placing surplus funds and the financial losses of the organization from the depreciation of funds in conditions of 
inflation (in periods of significant excess of the values of positive cash flows over negative ones)

Cash flow forecasting is the most poorly understood problem in financial science. It is closely related to both the strategic planning of the development of the enterprise in the future, and with the implementation of long-term financial planning.

Cash flow forecast consists in determining the possible sources of income and directions of spending money. Proceeding from the fact that most of the indicators are rather difficult to predict with great accuracy, cash flow planning comes down to drawing up a budget for cash in the forecast period, taking into account only the most important flow parameters: sales volume, share of proceeds from sales in cash, forecast of accounts payable ... The forecast is carried out for a certain period: for a year (with a breakdown by quarters); per quarter (broken down by months); per month (broken down by decade). 